Gut, 1977, 18, 301-302

\title{
A search for volatile nitrosamines in East African spirit
}

\author{
T. A. GOUGH
}

From the Laboratory of the Government Chemist, London

SUMMARY Spirits from areas of high and low incidence of cancer of the oesophagus were examined for volatile nitrosamines using a chemiluminescent detector. No nitrosamines were found, the detection limit being $0.001 \mu \mathrm{g} / \mathrm{ml}$.

There are wide variations in the occurrence of cancer of the oesophagus within East Africa and the possibility that this could be associated with the drinking of alcohol has been considered by various workers. Nitrosamines are well established carcinogens and have been shown to give rise to cancer of the oesophagus in a variety of species (Magee and Barnes, 1967; Magee, 1971). In a previous joint communication from this laboratory with Guy's Hospital and University College Hospital Medical Schools (Collis et al., 1971), it was reported that a number of spirits from high and low incidence areas of East Africa were analysed for the presence of volatile nitrosamines. No nitrosamines were detected in any of the spirits even after concentration. The detection limit was $5 \mu \mathrm{g} / \mathrm{ml}$ in the concentrates, which represented $0.1 \mu \mathrm{g} / \mathrm{ml}$ in the original spirits. The analytical procedure for the estimation of nitrosamines has been significantly improved since this work was carried out, and a detection limit of $0.001 \mu \mathrm{g} / \mathrm{ml}$ is feasible. Several of the spirits have been re-examined using the new technique.

\section{Analysis}

Five of the bulked spirits collected during the previous exercise are still available and are representative of spirits collected from areas of high (Northern Nyanza), high-moderate (Southern Nyanza), low (South-east Uganda), and very low (Teso-Karamoja and Nkole-Kigezi) occurrence. These were referred to as bulked spirits references $D$, $\mathrm{C}, \mathrm{G}, \mathrm{H}$, and $\mathrm{F}$ respectively in the previous work. In the intervening period they have been stored in brown glass bottles in a dark room at $+10^{\circ} \mathrm{C}$.

Received for publication 12 October 1976
Standard dilute solutions of nitrosamines stored for a similar period under the same conditions have not deteriorated markedly, and it is therefore a reasonable assumption that any nitrosamines which may have been present in the fresh spirits are still likely to be present.

The analytical procedure used to re-examine the spirits is based on the chemiluminescent reaction between ozone and nitric oxide which is generated by the cleavage of the N-NO bond in the nitrosamine. Specificity toward nitrosamines is given by the chromatographic retention time, the production of nitric oxide and its subsequent reaction and light emission.

A Pye 104 gas chromatograph containing a polar column was connected in series with a thermal energy analyser (TEA) model 502. Chromatographic effluent was passed into a catalytic chamber at $400^{\circ} \mathrm{C}$ and then into a cold trap at $-130^{\circ} \mathrm{C}$ to remove extraneous organic compounds from any nitric oxide generated from nitrosamines. The nitric oxide was reacted with $0.3 \%$ ozone in oxygen in a chamber under a vacuum of 1.2 torr. The resulting chemiluminescence was detected by a photomultiplier tube behind a $600 \mathrm{~nm}$ filter in this chamber, and the signal displayed on a potentiometric recorder. Concentrations of nitrosamines may be calculated from this signal, after calibration of the instrument using standard solutions of nitrosamines.

Each of the five samples was analysed using this apparatus and no volatile nitrosamines were detected. In the case of mass spectrometry it is necessary to search for particular nitrosamines and those studied in the previous report were the lower dialkyl nitrosamines and $\mathrm{N}$-nitrosopiperidine. Since the response of the TEA depends upon the presence of nitric oxide, it will detect any nitrosamine which is sufficiently volatile to pass through a gas chromato- 
graphic column. It is not restricted to specific nitrosamines.

It is concluded that there are no volatile nitrosamines present above $0.001 \mu \mathrm{g} / \mathrm{ml}$ in the African spirits from either the high or low areas of incidence of cancer of the oesophagus.

The loan of the TEA from the National Cancer Institute (USA) under contract NO1-CP-65795 is gratefully acknowledged. The Government Chemist is thanked for permission to publish this paper.

\section{References}

Collis, C. H., Cook, P. J., Foreman, J. K., and Palframan, J. F. (1971). A search for nitrosamines in East African spirit samples from areas of varying oesophageal cancer frequency. Gut, 12, 1015-1018.

Magee, P. N. (1971). Toxicity of nitrosamines: their possible human health hazards. Food and Cosmetics Toxicology, 9, 207-218.

Magee, P. N., and Barnes, J. M. (1967). Carcinogenic nitroso-compounds. Advances in Cancer Research, 10, 163-246. 